\title{
Ageing towards meaningful work? Age, labour-market change, and attitudes to work in the Swedish workforce, 1979-2003
}

\author{
Johan Örestig \\ Department of Education \\ Umeå University, Sweden \\ Email: johan.orestig@umu.se
}

\begin{abstract}
A central finding in earlier research on work orientation is that there are substantial age-differences regarding attitudes to work. Generally, more older workers describe their jobs as intrinsically meaningful than younger workers. This result has been interpreted in three different ways, the psychological, the cultural, and the structural hypotheses, where the first emphasizes cognitive age-differences, the second sees age-differences as outcomes of generational differences, and the third regards them as expressions of labour-market inequalities. These different approaches lead to quite different hypotheses regarding recent developments, but the relevant research is limited. Drawing on data from the Swedish survey of living conditions (ULF), this study has examined attitudinal change within the Swedish workforce during 1979-2003. Three sub-periods, 1986-1987, 1994-1996, and 20012003 were compared with 1979, the year of reference. The results showed that a consistently smaller share of the workforce held extrinsic work values in the subsequent periods, and that this applied to all age-groups. Further, the results did not support the assumption of broader cultural differences between generations. Rather, the results provide support for the structural hypothesis. Older workers held extrinsic work values to a lesser degree than younger workers regardless of period. Most strikingly, the gap between the youngest group on the labour market (ages 16-29) and the older groups widened during the period. Furthermore, class differences in
\end{abstract}


the distribution of the extrinsic attitude were intact throughout the study period; manual employees were consistently more likely to hold an extrinsic attitude than were service-class employees. This implies that differences in the probability of extrinsic work attitudes have been identifiable regardless of period, but that their prevalence has decreased as jobs involving features related to extrinsic work values have decreased since 1979.

Keywords: age, work attitudes, labour-market change

\section{Introduction}

A growing branch of research revolves around individuals' subjective evaluations of work, for example, orientation to work (Esser, 2005; Svallfors et al., 2001), commitment to employment (Hult, 2004) or motivation for working (Twenge et al., 2010). There are a variety of reasons behind the growth in this area of research. First, there is an empirical argument based on the assumption that attitudes are important determinants behind productivity, work motivation, and retirement patterns. Since the 1980s, The Organisation for Economic Co-operation and Development (OECD) has argued for the need both to increase the level of participation in the labour market among older workers and to postpone retirement (OECD, 2006, 1988). Having meaningful work is expected to increase the likelihood for a longer work life (Gould et al., 2008). Secondly, there is what can be called an argument of 'governmentality', a term borrowed from Foucault (2007). From this perspective, knowledge about the social determinants of attitudes can be used in policies to adjust attitudes towards policy goals (in favour of postponing retirement) (Nordenmark \& Stattin, 2009). Thirdly, there is an emancipatory argument. The point of departure here is that inequalities in the social division of labour deprive disadvantaged people of their right to a dignifying, selfimproving, and stimulating job. From this perspective, attitudinal measures serve as indicators of progress in a long-term attempt to balance inequalities that stem from the social division of labour (Bolton, 2007; Sayers, 2002; Alvesson \& Willmott, 1992; Braverman, 1974). 
A central finding in earlier research on subjective evaluations of work is that attitudes are strongly related to age: the older the individual, the more intrinsic the attitude. In other words, older workers have a greater tendency to emphasize work as rewarding in itself, in the sense that it offers meaningful, enriching, and stimulating work tasks and social contacts. By contrast, younger people are more likely to hold extrinsic attitudes, emphasizing external outcomes resulting from having a job, such as the pay or other opportunities associated with working (e.g., Hult \& Svallfors, 2002; Svallfors et al., 2001; Mathieu \& Zajac, 1990). Three different explanations for the differences in attitudes have been put forward, which I refer to as the psychological, the cultural, and the structural hypotheses. The psychological hypothesis rests on socioemotional selectivity theory, a life-span approach in which it is argued that individual's subjective evaluations change when they reach an advanced age. Advanced age is associated with a re-evaluation of time followed by motivational changes (e.g., Carstensen \& Mikels, 2007). The cultural hypothesis is a line of theory and research which emphasizes the importance of generation. From this point of view, age-differences reflect that different age-groups belong to different cohorts. The fact that different cohorts established themselves on the labour market in different historical periods, each of which was dominated by a particular set of norms and values about work, should be reflected in age-differences regarding attitudes (Twenge et al., 2010; Stamov-Roßnagel \& Hertel, 2010; Lubinski, Schmidt, \& Benbow, 1996; Meglino \& Ravlin, 1998). The structural hypothesis explains age-differences as reflections of structural conditions in the labour market. From this perspective, agedifferences in work attitudes mirror an unequal distribution of healthpromoting, stimulating, and enriching jobs between different agegroups rather than psychological or cultural (i.e., generational) differences (Bolton, 2007; Ebbinghaus, 2006; Sayers, 2005).

The literature in this field is theoretically rich but empirically poor. A central reason for this is the lack of data required for repeated crosssectional or longitudinal analyses. Consequently, earlier research has predominantly been based on cross-sectional data from a single timepoint. Such research has enhanced our understanding of how working conditions, institutional configurations of the welfare state, and the structure of the labour market influence attitudes towards work (Edlund \& Hult, 2008; Esser, 2005; Hult, 2004). However, since these studies lack a temporal dimension they do not inform us about attitudinal change in relation to age. Therefore, such research fails to explain whether attitudes within a given context (for example a country 
or region) have changed across time and, if so, in which direction and for what reasons? This gap between theory and research is particularly problematic considering the substantial changes that the labour market in general, and the composition of the workforce in particular, have undergone during recent decades, that is, the relative growth of the service sector and the increasingly heterogeneous character of the labour force (Mulinari \& Neergaard, 2004; Åberg, 2004).

This is a case study of developments in attitudes to work for different age-groups during the period 1979-2003 in Sweden. The main idea behind the study design has been to examine the validity of the psychological, cultural, and structural hypotheses by following developments for different cohorts across this period. More specifically, the aim has been to analyse (i) changes in the prevalence of extrinsic and intrinsic attitudes towards work for different agegroups and (ii) to what extent such changes follow patterns that can be expected from the different hypotheses, as well as (iii) to what extent these developments can be understood using the structural hypothesis, that is, as a reflection of labour-market change. The analysis is based on comparisons between four distinct sub-periods: 1979, 1986-87, 1994-96, and 2002-03. An analysis of how attitudes towards work are distributed within different age-groups in the different sub-periods makes it possible to examine and compare general developments for different cohorts.

The main contribution of the present study is that it covers a longer time span than previous research (Twenge et al., 2010; Berglund, 2001). The design also enables examination of continuities and disruptions in attitudinal change, while relating these developments to parallel changes in the structural conditions of the labour market. Thus, the aim is not just to examine if attitudes to work are differentiated between different age-groups, but also to discern how these differences have evolved across time and to identify important driving forces behind such developments.

\section{Theoretical framework and earlier research}

In considering work centrality (i.e., the generalized importance of wage labour in people's lives) in advanced capitalist welfare states, theorists and researchers have paid particular attention to values 
related to work (Noon \& Blyton, 2007). Work values have been defined as the outcomes people desire and feel they should attain through work' (Twenge et al., 2010, p. 1122). However, the latent nature of values makes them difficult to measure. One common way to get around this is to use attitudes as proxies for underlying values (Thompson \& McHugh, 1990, p. 273ff.).

Attitudes have been defined as individuals' motivational orientations, consisting of three components: '(1) cognitive, our thoughts about an issue; (2) affective, the emotions associated with the issue; and (3) behavioural, how we behave with respect to the issue' (Goldstein, 1994, p. 733). Social psychological theory and research suggest that attitudes emerge from a complex and dynamic interplay between the individual's experiences, memories, and underlying values and the social context in which they are expressed. Hence, research on attitudes by definition calls for a inter-disciplinary approach, including psychology, sociology, and economics (Thompson \& McHugh, 1990, p. $262 \mathrm{ff}$.).

Earlier cross-sectional research and cross-country comparisons show that attitudes to work are indeed strongly related to social-background factors (e.g., Stamov-Roßnagel \& Hertel 2010; Hult \& Svallfors, 2002; Svallfors et al., 2001; Mathieu \& Zajac, 1990). As stated above, one central finding is the significance of age: older age-groups are more likely to emphasize intrinsic rewards than younger age-groups are. This is not the same thing as saying that workers hold either intrinsic or extrinsic attitudes. On the contrary, work situations are made composed of various conditions, work tasks, and relationships, where an individual might express both intrinsic and extrinsic rewards depending on which dimensions are taken into consideration. Furthermore, the research cited above suggests that when people are asked about how they view work in general, older workers tend to emphasize intrinsic rewards from their job to a greater extent than younger workers do.

Why, then, should we expect age-based differences in attitudes to work? As discussed in the introductory section, the psychological, the cultural, and the structural hypotheses suggest explanations from rather different perspectives. The most general answer is provided by recent psychological research which has demonstrated a general socalled positivity effect in older people's reconstructions of past events and attitudes (Carstensen, Isaacowitz, \& Charles, 1999). Drawing on the theory of socioemotional selectivity, a life-span theory that focuses 
on how temporal horizons shape human motivation, Carstensen et al (1999) argue that individual goals are developed in relation to temporal contexts. This means that one's perception of time will affect one's cognitive appraisals of one's life situation, focus, priorities, and goals. On the one hand, younger people tend to perceive time as expansive since they have many life choices ahead of them, thus having mindsets that are focused on preparing for the future. On the other hand, older people tend to perceive time as limited, a perception strongly related to a reorientation towards emotionally grounded goals. Advocates of the positivity effect add that such goals follow a particular pattern; they are biased towards positive and meaningful goals that offer emotional equilibrium, and based on the desire to lead a meaningful life, to seek out and to invest in emotionally intimate social relationships and to achieve and maintain social connectedness. Older people adapt cognitive appraisals to the aim of regulating emotional experiences (Mather \& Carstensen, 2007; Carstensen \& Mikels, 2005; Carstensen et al., 1999). Consequently, the psychological hypothesis should expect persistent agedifferences, regardless of time period.

Despite having different roots and standpoints, the cultural and structural hypotheses share the assertion that attitudes must be situated with regard to the immediate social context surrounding the individual. In other words, attitudes are reflections of the norms, values, and conditions that structure our lives. How is this possible? The influential theory of cognitive consistency argues that human beings have an inherent desire to be consistent in attitudes and behaviour. If there is some inconsistency between what we think is good, morally right or legitimate and what we actually do, we tend to adapt our attitudes so that they are in line with our life situation. Alternatively, we act to change our surrounding environments and conditions so that they allow us to act in accordance with our underlying values. In the field of work attitudes, we are dealing with a process of cognitive (in)consistency if the everyday reality of work in which we are situated acts as 'an irritant of a stimulus that motivates us to modify or change them [attitudes] until they form a coherent if not logical package' (Atkinson et al., 1990, p. 703). From this perspective, the close relationship between attitudes to work and factors of the surrounding social context is understood as one in which attitudes reflect or tend to be adjusted toward the structural and cultural conditions in which they are expressed. 
The cultural hypothesis is a line of theory and research which (i) assumes that work attitudes are socially informed and (ii) underlines the importance of generations as historically distinct results of sociocultural influence. A generation can be defined as a cohort that includes individuals who were born in the same period and have distinctive social or historical life events in common (e.g., Schaie, 1965). The common features of each generation are influenced by a number of forces (i.e., parents, peers, media, critical economic and social events, and popular culture). These forces create common values among the cohort, distinguishing them from younger and older generations. A general understanding of values is that these include learned, general, impervious, ends-oriented tendencies to choose some alternatives of action rather than others. Understood in this way, they represent standards of behaviour towards which the individual has a strong positive attitude (Liu \& Lay, 2012). Different generations face different experiences and events during their lives, and this might, in turn, generate different experiences, expectations and values about work that are then expressed as generational differences of attitude (Cennamo \& Gardner, 2008; Lubinski, Schmidt, \& Benbow, 1996; Meglino \& Ravlin, 1998). In a recent study from the United States, Twenge et al. (2010) compared work values of three different generations born after World War II and found that leisure values (i.e., extrinsic values) increased steadily over the generations, while work centrality and emphasis on intrinsic work values declined.

There are several different strands of theories that fit the cultural hypothesis. Most importantly, labour-market researchers have argued that, in the decades following the economic crisis in the 1970s, postwar European welfare states established 'early exit cultures', in which work values were undermined and early retirement was established as a social right (Guillemard et al., 2004; de Vroom et al., 2002). In addition, Laslett (1989) introduced the concept of the 'third age' to distinguish a new generation of healthy and relatively wealthy pensioners that laid the basis for a normative shift through which retirement is increasingly associated with self-realization. The cultural hypothesis is sometimes combined with moral-hazard theory, which assumes that attitudinal change should develop in a particular direction since generous social security is expected to undermine work values and because people, to a growing extent, seek selfrealization outside work (e.g., SOU, 2011:48; Noon \& Blyton, 2007; SOU, 2004; Kreuger \& Meyer, 2002; Lindbeck, 1995). This view, at least in part, explains attitudinal change as an expression of generational differences. If self-realization takes place more and more 
often outside work, there is room for an increase in extrinsic work attitudes; that is, work is to a greater extent viewed as a means for individuals to obtain resources to fulfil needs and desires during leisure time. This implies persistent differences between generations regarding their views on work.

From a rather different angle, the structural hypothesis underlines how attitudes towards work are related to conditions of the labour market. Working conditions and work content are central social determinants for how we view our work. Earlier research shows that work attitudes in general, and intrinsic and extrinsic work attitudes specifically, relate to class position, educational level, working conditions, gender, and type of work. In general, with higher social position, better working conditions and greater control over one's work, more positive attitudes towards work should follow (e.g., Gould et al., 2008; Edlund \& Hult, 2008; Vogel \& Stattin, 2006; Svallfors et al., 2001; Johansson, 1997; Herzberg et al., 1993).

The different structural conditions that different age-groups are exposed to explain age-differences in attitudes to work. Working conditions are unequally distributed across age-groups. Younger people tend to hold jobs with poorer working conditions and lower employment security, but, since most working people advance throughout their working life, they are likely to express rather different attitudes in later years. Other explanations suggest that many older people find that they are less competitive on the labour market than their younger colleagues, and therefore place a higher value the job that they have (Ebbinghaus, 2006). Furthermore, age differences can reflect selection effects. For example, older people of working age, who have poor health and are in professions with difficult working conditions, are more likely to be excluded from the workforce than they would have been at younger ages. Therefore, a comparison between the oldest age-group with younger ones (where those worst off are still included) might indicate that the oldest age-group is a particularly satisfied group (e.g., Mathieu \& Zajac, 1990; Hult \& Svallfors, 2002).

Moreover, general changes in the distribution of attitudes across time are understood as a reflection of structural changes on the labour market. For example, different cohorts enter the labour market under different conditions, which can affect their experiences of and views on work. If labour-market conditions affect the distribution of work attitudes, changes in the labour market should be followed by 
attitudinal change. From this perspective, age-differences in work attitudes reflect an unequal distribution of stimulating and enriching jobs between different age-groups rather than cultural or generational differences (Noon \& Blyton, 2007; Berglund, 2001).

Thus, there are competing hypotheses and explanations for why attitudes towards work are unequally distributed between different age-groups. Cross-sectional studies which are limited to a single measurement point of time consistently show that structural conditions are influential but fail to rule out the possibility that age-differences stem from psychological differences between age-groups or cultural differences between generations. Longitudinal studies which follow developments for a single cohort over time fail to show whether the observed pattern only applies to the cohort in focus or if it can be generalized (Schaie, 1965, p. 95). The best way to research this further is to follow developments over time while distinguishing psychological, cultural, and structural control factors. Focus is placed on ageing-effects as well as cohort-effects. Ageing-effects refer to the age-differences within a cohort, for example, how attitudinal patterns for those aged 16-29 differ from those of other age-groups at a single period. Are ageing-effects distributed similarly at different periods or did they change across time? Cohort-effects refer to differences in attitudinal patterns between the same age-groups measured at different periods, for example, how those aged 16-29 at a particular period differ from those aged $16-29$ at other periods.

If psychological factors are central, we should expect stable agepatterns, regardless of period. If cultural factors are central, we should expect that people hold stable attitudes while they age, and that the distribution of attitudes will be different for a cohort of older workers at one point of measurement than for another cohort of older workers at a subsequent point. Last, but not least, if structural factors are central, attitudes for different cohorts should change with improved or worsened structural conditions. Before the study design is presented more closely, a general background on the Swedish case is presented, with a focus on labour-market change during the study period. 


\section{Background: labour-market change in Sweden, 1979- 2003 and study design}

Sweden is a suitable choice for a case study on attitudinal change in relation to structural factors as the country has undergone substantial changes in its labour market from the 1970s onward. Before discussing these changes in detail, a general illustration of developments regarding labour-market participation is relevant as a background. Figure 1 shows how the labour-market participation of the oldest age-groups has changed throughout the study period.

Figure 1. Labour-market participation rates for men and women, 1979-2003.

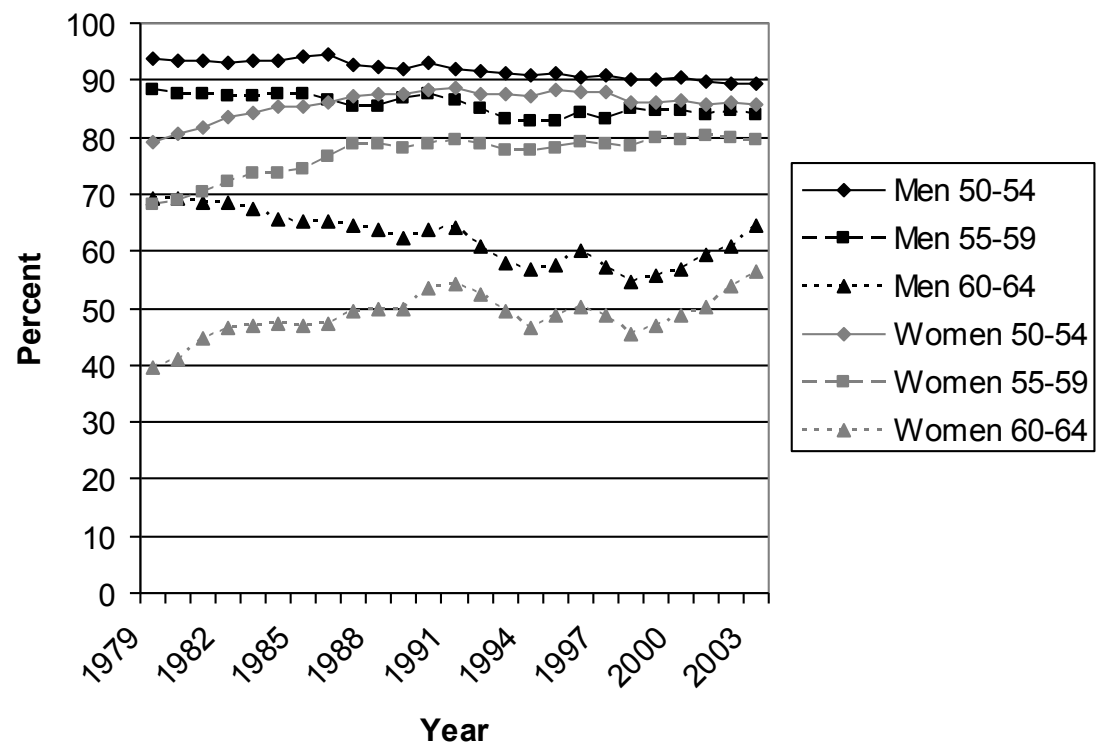

Source: Based on the author's own calculations of the OECD's (2010) labourforce statistics.

This period is characterized by changes in respect of both the job structure and the composition of the workforce. First of all, Åberg (2004) finds substantial changes in the Swedish job structure between the middle of the 1970s and the early 2000s. He shows that the number of jobs with high rates of pay, that require higher levels of 
education, has increased, while the number of jobs with lower rates of pay, that require lower levels of education, has decreased.This process was accentuated during the economic recession that took place in the 1990s. In this sense, Sweden diverged from the trend in other countries, such as the United States, where the job structure changed more unevenly (Benner, M. \& Bundgaard Vad, 2000). This can be explained by a number of characteristics that obstructed the emergence of low-paid jobs in Sweden during this period, that is, the influence of trade unions on income policies, tax levels, social protection, and outsourcing of low-paid or unskilled jobs to other countries (le Grand et al., 2002). Moreover, the work environment changed during the study period but not unambiguously. Vogel (2006) shows that, in general, the self-reported physical work environment improved during the period 1980-2003. These improvements were more profound among men than among women. The self-reported psychosocial work environment developed more unevenly. The psychosocial demands of work increased dramatically during the late 1990s, which resulted in rising long-term sickness absence. This was mainly a consequence of rationalizations in the public sector as a response to the economic recession (Lidwall, 2011). Also, the gender and age composition on the labour market changed dramatically. In general, women's and older workers' labour-market participation increased. Women primarily entered into the labour market within the expanding public sector (education, child care, elderly care, etc.), which also meant that the labour market was increasingly gendersegregated (Daly, 2000).

Thus, the Swedish case is suitable for the study of changes in age patterns of work attitudes. By examining attitudinal change we can analyse if actual developments coincide with those that can be expected from the different hypotheses. Also, by introducing a set of control variables related to structural conditions, we can examine the extent to which observed changes are related to labour-market change.

\section{Data, included variables, and method}

The dataset used here comes from the Survey of Living Conditions in Sweden (ULF), conducted by Statistics Sweden (Vogel \& Häll, 2006). The ULF has been conducted annually since 1975 and includes a large set of variables on work environment, housing, economy, health, 
leisure, material assets, civic activities, social relations, employment and work time, education, security, transportation, and communication. The dataset is based on a random sample of approximately 7500 respondents per year, comprising adults aged 16 and older.

Cross-sectional data are used in the analysis. As stated above, the years included are clustered into four sub-periods: 1979 (I), 1987 (II), 1994-1996 (III), and 2001-2003 (IV). The fact that the ULF comprises a rich set of information and covers a relatively long time span offers unique possibilities for analysing long-term trends, in this case changes in the distribution of attitudes to work. The sample consists of employed individuals, as the focus is on how working people valued the work they held at the time when the survey was performed. Table 1 displays the frequencies for age-groups distributed according to the analysed sub-periods.

Table 1. Included cases ( $\mathrm{n}$ ) distributed by age-group and period.

\begin{tabular}{ccccc}
\hline Age-group & 1979 & 1987 & $1994-1996$ & $2001-2003$ \\
\hline $16-29$ & 1746 & 1118 & 2235 & 2044 \\
$30-39$ & 1346 & 1192 & 2898 & 2617 \\
$40-49$ & 2006 & 1187 & 2595 & 2475 \\
$50-54$ & 636 & 409 & 1322 & 1305 \\
$55-59$ & 563 & 371 & 979 & 1286 \\
$60-65$ & 419 & 323 & 621 & 794 \\
Total & 6716 & 4600 & 10650 & 10521 \\
\hline
\end{tabular}

Table 1 shows that developments for six different age-groups: 16-29, $30-39,40-49,50-54,55-59$, and $60-65$ are examined. Table 2 shows which birth cohorts the different age-groups represent for the different periods. 
Table 2. Age-groups, birth-year, and sub-periods

\begin{tabular}{ccccc}
\hline Age-groups & 1979 & $1986-87$ & $1994-96$ & $2001-2003$ \\
\hline $16-29$ & $1950-1963$ & $1957-1971$ & $1965-1980$ & $1972-1987$ \\
$30-39$ & $1941-1949$ & $1947-1957$ & $1955-1966$ & $1962-1973$ \\
$40-49$ & $1930-1939$ & $1937-1947$ & $1945-1956$ & $1952-1963$ \\
$50-54$ & $1925-1929$ & $1932-1937$ & $1940-1946$ & $1947-1953$ \\
$55-59$ & $1920-1924$ & $1927-1932$ & $1935-1941$ & $1942-1948$ \\
$60-64$ & $1915-1919$ & $1922-1927$ & $1930-1936$ & $1938-1943$ \\
\hline
\end{tabular}

The oldest individuals within the sample were born in 1938 and reached the former statutory, and still most common, age of retirement, 65, in 2003, the last year in the fourth sub-period. The youngest individuals within the sample were born in 1987 and turned 16 in 2003. Thereby, the data cover an age-span of 49 years, from the oldest to the youngest individuals, and people born during the period 1938-1963 are represented in all sub-periods included in the study.

The dependent variable, 'attitude to work', is based on the following survey question:

Which one of the following sentences best describes your experience of your current work situation?

(i) This job is like any other job. You do what is expected of you, but the only thing that matters is the earnings.

(ii) There is something special about this job. Apart from the earnings, it gives me a feeling of personal satisfaction.

Those who identified themselves with the first description were placed in the extrinsic attitude category. Those who chose the second description were placed in the intrinsic attitude category. Thus, the extrinsic and intrinsic dimensions of work are treated as dichotomous. However, it should be pointed out that this is a simplification in relation to the empirical world. For real working people of flesh and blood, such a distinction is not as clear-cut. In fact, people can be motivated by both extrinsic and intrinsic rewards in their work. A continuous measure that allows individuals to appreciate the degree to which they hold extrinsic and intrinsic attitudes might be preferable, but that is not 
an option given the arrangement of available data. Additionally, a dichotomous measure has the advantage of identifying and illustrating how the centre of gravity in attitudinal formation within the workforce is distributed. Regarding the specific variable used in the present study, it should be pointed out that 'attitude towards work' refers to an individual's attitude towards his or her actual work situation at the time the survey data were collected. Other measures often refer to extrinsic orientation towards paid labour in general (e.g., Hakanen et al., 2006; Esser, 2005; Hult, 2004; Berglund, 2001).

The included independent variables are as follows: (A) Period; (B) Gender: male or female; (C) Class: unskilled workers, skilled workers, service class III, II, and I; (D) Sector: privately employed, stateemployed, county-council or municipality-employed; (E) Physical work environment: high exposure, medium exposure, low exposure; and (F) Psychosocial work demands: high exposure, medium exposure, low exposure. The main variable is 'period' since we are interested in developments over time.

The circumstances associated with some of the independent variables call for some comments. The choice of included periods is partly pragmatic due to restrictions in the data, that is, the fact that the dependent variable of 'attitude towards work' is not accessible every year between 1979 and 2003. Ideally, the periods included in the analysis should include more recent years and sub-periods. Indeed, ULF-data is available for 2010-11 but, unfortunately, the dependent variable used has not been included in the survey since 2006, and that year does not include a sufficient number of cases to meet the necessary conditions for an additional sub-period. These limitations aside, the aim was (i) to cover a longer time than previous research, (ii) to distinguish a maximum number of cohorts for comparison, and (iii) to choose measuring points which capture important events related to changes of structural conditions in the Swedish labour market. The reference year of 1979 represents a time when the Swedish social-security system was established, and the subsequent periods capture fluctuations in Sweden, such as the high labourmarket participation in the 1980s, the economic crisis and the mass unemployment of the early 1990s, and the economic recovery in the late 1990s (Holmlund, 2006).

The remaining independent variables are indicators of structural position and conditions and were selected as control variables on the basis of previous research (e.g., Twenge et al., 2010; Esser, 2005; 
Hult, 2004). The class variable is based on the Swedish SocioEconomic Code (SEI), a classificatory system developed from data on occupation, working conditions, and education (Bihagen, 2000). Service classes are organized in three categories. Service class I includes professionals and other higher non-manual employees, service class II includes intermediate non-manual employees, and service class III includes assistant non-manual employees. The variable physical work environment is an index (Cronbach's alpha of .63) composed of five measures. Respondents were asked both whether they were exposed to heavy lifting, dirt, vibrations, and bentover working postures and to what extent their work tasks call for exertion to the point of sweating. The respondents were grouped into the three subgroups - high, medium, and low exposure - on basis of the number of 'yes' answers given. Finally, the variable 'psychosocial demands' is an index (Cronbach's alpha of .94) based on individual exposure to psychological strain, time-pressure, and monotonous work tasks; the classification of individuals is based on the same principle used for physical work environment.

To observe associations between the independent variables and attitude to work, we shall estimate logistic regression models in which the different periods are included as independent variables. In this study, odds ratios are presented. This means that we can determine whether the analysed category's distribution over the dependent variable corresponds to or diverges from the distribution of the reference category (Hosmer \& Lemeshow, 2000). Through the multivariate analysis, the relative importance of the remaining independent variables is controlled for. The inter-period comparison is done using cross-sectional analysis, in which periodic change for the three latter periods is expressed as the change in the probability to hold extrinsic work values in relation to the reference year 1979. Periodic change will be presented separately for the six age-groups, namely, 16-29, 30-39, 40-49, 50-54, 55-59, and 60-65.

\section{Results}

This section examines the periodic development of attitudes towards work among older workers. By way of introduction, descriptive statistics for various key groups in the Swedish workforce are presented and discussed. There is a focus on ageing-effects as well as cohort-effects. Thereafter, multivariate models are employed to 
determine whether periodic change can be identified when factors related to workforce changes are controlled for.

Table 3 displays the distribution of the extrinsic attitude in workforce subgroups, that is, men, women, and various age-groups in four different periods.

Table 3. Workforce subgroups: percentages with extrinsic work values in Sweden in 1979, 1987, 1994-1996, and 2001-2003, and distributed by workforce, gender, and age-group.

\begin{tabular}{lcccc}
\hline & 1979 & $1986-1987$ & $1994-1996$ & $2001-2003$ \\
\hline Workforce & 25.3 & 21.5 & 19.5 & 19.2 \\
Women & 21.8 & 18.9 & 16.2 & 16.2 \\
Men & 28.8 & 24.0 & 23.0 & 22.2 \\
& & & & \\
Age-group, & & & & \\
years & & & & \\
16-29 & 33.7 & 30.7 & 31.2 & 32.8 \\
30-39 & 21.6 & 17.4 & 15.6 & 16.0 \\
$40-49$ & 23.9 & 19.8 & 18.7 & 18.7 \\
$50-54$ & 18.9 & 17.6 & 14.5 & 12.7 \\
$55-59$ & 24.4 & 21.3 & 14.5 & 15.6 \\
$60-65$ & 19.7 & 13.5 & 14.8 & 10.4 \\
\hline
\end{tabular}

The results in table 3 indicate that, for the working population as a whole, there is a downward trend for the extrinsic attitude, from 1979 to 2003. In other words, more people reported that they found their work intrinsically meaningful rather than economically rewarding. The proportion of individuals with an extrinsic attitude decreased from 25.3 per cent in 1979 to 21.5 per cent in 1987 , stabilizing at approximately 19 per cent in the last two periods. Throughout the time period of the study, a substantially larger proportion of men than women held an extrinsic attitude.Table 3 also shows developments for different agegroups. Figure 2 shows how attitude to work was distributed across different age-groups for each included sub-period. 
Figure 2. Developments for the prevalence of the extrinsic attitude between age-groups in four different sub-periods, 1979-2003.

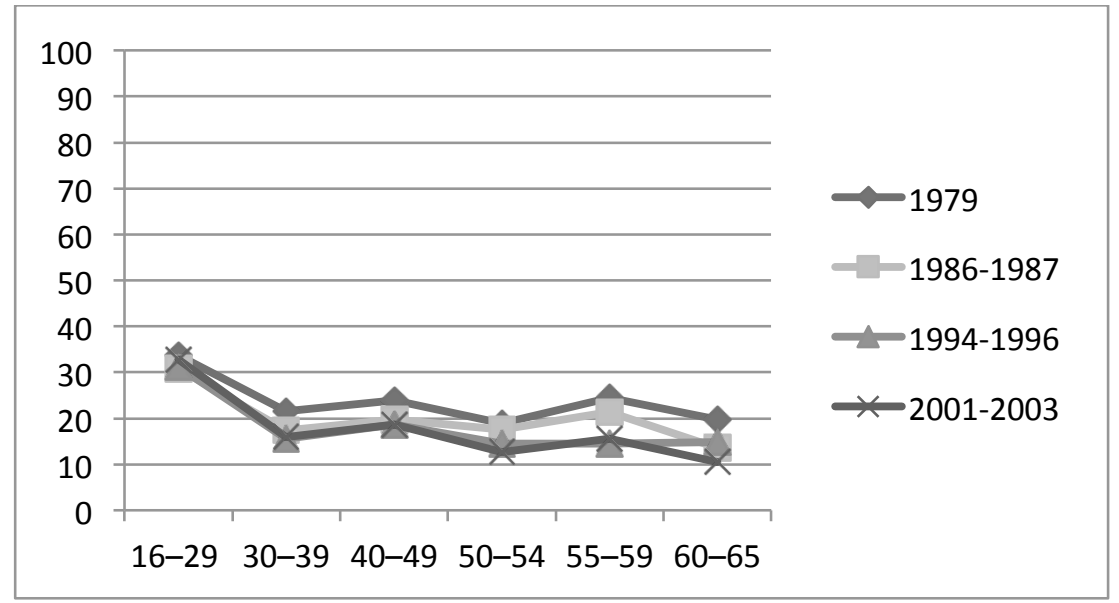

Regarding the three different hypotheses, we may recall that they imply different expected patterns. First, the psychological hypothesis implies stable differences between younger and older workers. Secondly, the cultural hypothesis suggests that we should expect differences in how the same age categories within different cohorts report attitudes, considering that they belong to different generations. Thirdly, the structural hypothesis suggests that attitudinal developments should follow labour-market developments.

The results presented in Figure 2 indicate no qualitative differences in how work attitudes are distributed in different age-groups, that is, a clear majority express intrinsic attitude for all groups at all subperiods. Rather, there is a distinctive general tendency for the proportion of the workforce possessing an extrinsic attitude to be lower, moving from the youngest to the older age-groups. But these age-effects are not linear; the proportion of people emphasizing extrinsic rewards is not consistently lower as the age of the age-group increases. For example, among working people aged 55-59 extrinsic attitudes are consistently more widespread than among working people aged 50-54. Also, the relationship between working people aged 30-39 and 40-49 is different for the different sub-periods. This implies that the consistent age-effect appears between the older agegroups and the youngest age-group. The centrality of this relationship 
is further demonstrated by the fact that differences between the older age-groups are smaller than they are in relation to the youngest category.

With regard to cohort-effects, the age categories older than 29 show a clear increase in individuals judging their work as intrinsically meaningful rather than as economically rewarding. For most groups, this trend applies to the three earlier sub-periods and seems stable between the third and the fourth sub-periods. The attitudinal change is substantial. In fact, in the oldest age-group, the proportion of working people with the extrinsic attitude was approximately ten per cent lower in 2001-2003 than in 1979. Again, the youngest age-group (16-29 years) stands out as the category in which the cohort-effects are most modest between different periods.

In sum, the descriptive analysis shows that a declining proportion of the Swedish working population holds the extrinsic attitude. More working people emphasize non-financial rewards when describing their work. Since this pattern is general, except for the youngest agegroup, the results deviate from the differences between cohort that would be expected from the cultural hypothesis, but are in line with what should be expected from the psychological and the structural hypotheses.

To deepen our understanding of this problem and to take structural factors into account, multivariate logistic-regression models have been estimated in which each of the four periods are included as an independent variable. In doing this, I have been able to isolate the periodic change in order to examine whether we can identify statistically significant changes in probability for extrinsic attitudes between time-points while controlling for factors related to the structural hypothesis, namely, gender, sector, social class, and work environment. Table 4 shows how these variables are related to the probability of an extrinsic attitude. In this article, the importance of the variable of period is of particular interest since it demonstrates whether a cohort-effect remains statistically significant when structural factors are held constant. The year 1979 constitutes the reference category, and the coefficients for the other periods express the change of the odds ratio when the rest of the independent variables are controlled for. 
Table 4. The probability of holding an extrinsic attitude depending on gender, period, physical work environment, psychosocial work environment, sector, and social class (1979-2003). Logistic regression (odds ratio). ExpB coefficients and $R^{2}$ values in percentages. Reference group in parentheses.

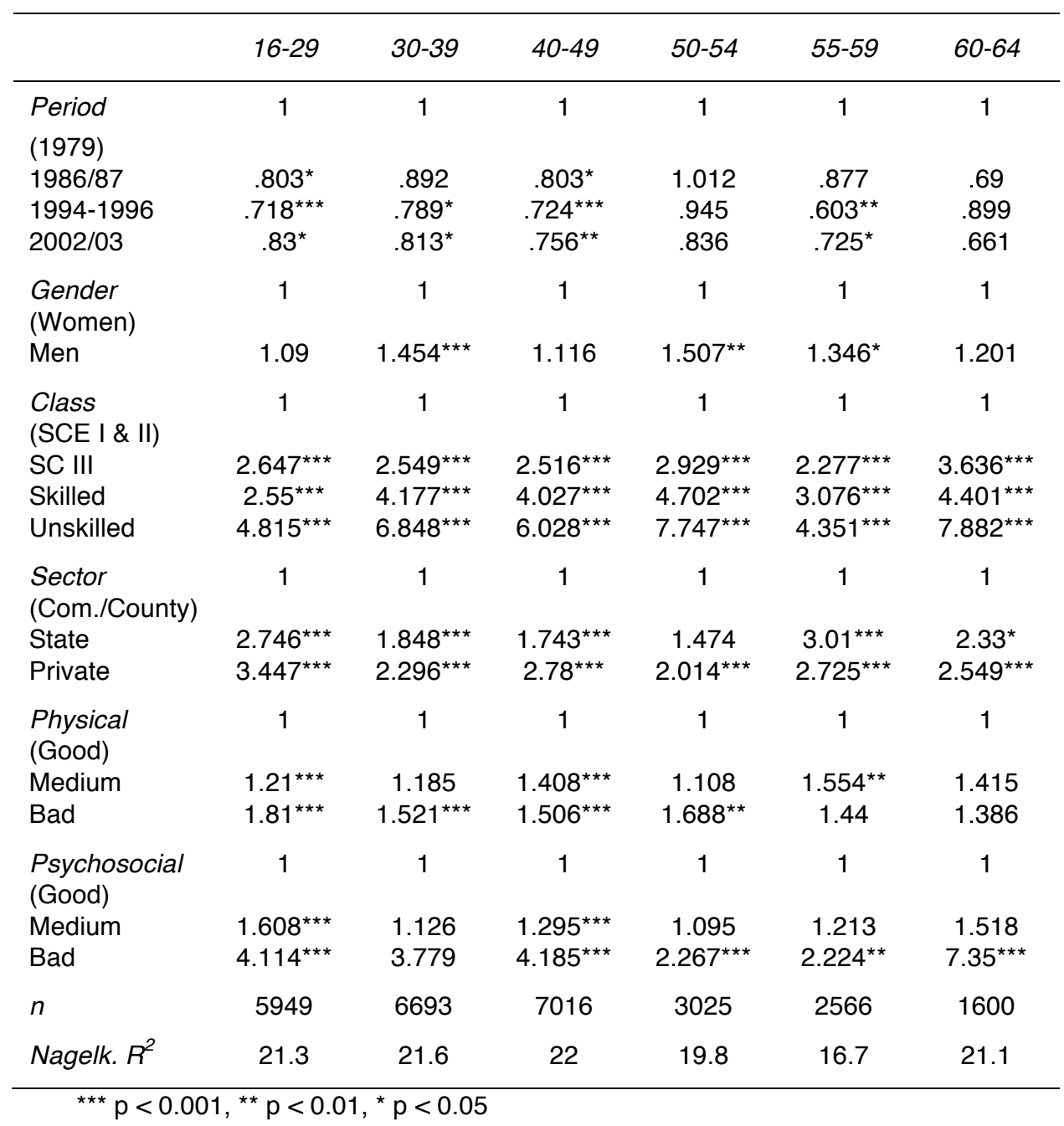

The results show that attitudes to work have indeed changed for several age-groups; that is, a cohort-effect can be observed. In all age-groups where the coefficients for period are statistically 
significant, however, the odds-ratio probability for extrinsic work attitude decreased. The results also show that the changes in attitudes are influenced by structural factors. Regarding cohort-effects, the oldest age-group, together with the age-group 50-54, displays no statistically significant periodic change when other independent variables are controlled for. In other words, the odds ratio of working people in these age-groups holding extrinsic work attitudes is neither greater nor less than it was in 1979. The four remaining age-groups, in some sub-periods, display statistically significant changes in relation to 1979. However, when this is the case, the odds ratio is consistently lower in the two last periods than it was in 1979. Most importantly, the youngest age-group shows a statistically significant decrease when structural factors are held constant. This implies that the indicated polarization between the youngest and the oldest agegroups is mainly explained by differences in class composition, work environment, and more.

Furthermore, the results presented in Table 4 underscore the general importance of structural conditions for understanding work values. There are strong and stable differences in the odds ratios for extrinsic work values between social groups, especially regarding social class and psychosocial work environment. These characteristics were important for every single age-group regardless of period. Another noteworthy result is that the higher odds ratio for an extrinsic attitude among men than women is no longer statistically significant within the youngest and the oldest age-groups and quite weak within the remaining age-groups.

Some remarks on the study design are warranted. In line with earlier research, the present study reveals significant differences between sub-categories, that is, the included control variables. There is a risk that there may be underlying tendencies that contradict the general results. For example, the odds ratio of extrinsic work values among worker subgroups may have changed significantly while the general trend has remained stable. Therefore, the various sub-categories have been separately analysed. These sub-categories include dichotomized versions of the control variables, that is, workers versus service-class employees, public-sector versus private-sector employees, men versus women, high versus low exposure to psychosocial demands, and high- versus medium- and low-strain physical work environment. The results of the separate analyses - which are not shown here display a striking stability. No single age-group in the various subcategories displays an increased odds ratio for extrinsic work 
attitudes. In other words, the analyses generated no support for the assumption that the odds ratio for extrinsic work attitudes has increased among workers in relation to service class employees, men in relation to women, and so on. The results confirm the findings of the general analysis of work values among the various age-groups. Despite all the changes in the Swedish labour market over the period 1979-2003, the attitudes of working individuals have been stable or strengthened in relation to the reference year and differences between groups have persisted.

\section{Concluding discussion}

This study analysed changes in attitudes to work for different agegroups in the Swedish workforce during the period 1979-2003. Earlier research shows that older working people generally express intrinsic rather than extrinsic work attitudes, while a substantially greater share of younger workers emphasize extrinsic rewards (e.g., Edlund \& Hult, 2008; Hult \& Svallfors, 2002; Mathieu \& Zajac, 1990), but there is limited research on how age-differences have evolved over time (Twenge et al., 2010; Berglund, 2001). There are competing theories about why attitudes to work are distributed in such a way and how they have changed during recent decades. The psychological hypothesis states that differences between younger and older people reflect age-differences in cognitive and motivational orientations. Younger people are generally oriented towards planning for the future, while older people emphasize emotional equilibrium. The cultural hypothesis emphasizes generational factors and norms concerning work. Different cohorts share different life events and conditions and this tends to generate generational differences in how work is valued. The structural hypothesis assumes that attitudinal change is driven by structural changes in the labour market. From this perspective, agedifferences in work attitudes reflect age-differences in working conditions. These different hypotheses imply different expectations on how work attitudes should have developed across time, but earlier research on how age-patterns in work attitudes develop over time is limited. To contribute to this discussion, developments for different age-groups were examined while factors related to structural change were taken into account. Thereby, the argument that we should expect changed age-patterns besides those that are explained by structural factors could be empirically tested. 
Results showed no signs of the attitudinal developments that would be expected from the cultural hypothesis. First, results indicated that the younger age-groups at all periods had a substantially higher proportion with an extrinsic attitude than older age-groups. Thus, the age-effects found in earlier research, that is, older workers to a lesser degree emphasize extrinsic rewards than do younger workers, remains valid for all periods included in this study. Secondly, results indicated that cohorts have different proportions of people with extrinsic attitudes at different periods. Thus, cohort-effects provided no empirical support for the stability of work attitudes within cohorts that is suggested by the cultural hypothesis.

The multivariate analyses that included structural factors as control variables indicate that the general pattern of decreased prevalence of extrinsic work values reflects general changes in job structure and the composition of the workforce. In comparison with the year of reference the subsequent periods are characterized by more high-skilled and well-paid jobs and an increase in emotional work at the expense of traditional industrial work, and such jobs are related to intrinsic rather than extrinsic work values. For several older age-groups, periodic change between one sub-period and the year of reference no longer are statistically significant when structural factors such as class, work environment, gender, and sector were controlled for. Thus, these results provided support for the structural hypothesis. Furthermore, such an argument is strengthened by the fact that there were strong and stable differences in the odds ratios for extrinsic work attitudes between social groups, especially regarding social class and psychosocial work environment. This implies that differences in the odds-ratio for an extrinsic attitude have been strong regardless of period. In other words, there have been no qualitative changes in the distribution of attitudes between age-groups. The changes should rather be understood as quantitative changes; the prevalence of the extrinsic attitude has decreased and the gap between the youngest group and the older groups, which was already there in 1979, has widened over time.

One important finding was the substantial difference between the youngest age-group, aged 16-29, and the older age-groups. Approximately one-third of the youngest group reported an extrinsic attitude, irrespective of sub-period. Given that the remaining agegroups show decreased levels of extrinsic attitude, the gap between the youngest and the older age-groups has widened over time. This result indicates that developments on the Swedish labour market have 
been towards a polarization between the relatively well-off middle aged and the youngest age-group who suffer from the poorest working conditions and hold the most extrinsic attitudes towards work. However, if we consider the psychological hypothesis, we may interpret this result as at least partly a reflection of different cognitive and motivational orientations between the youngest and the older agegroups. The design of this study does not allow for conclusions about the relative importance of psychological and structural factors, and these factors should be addressed in future research.

Of course, it should be pointed out that there are other limits to this approach. First, since this is a case study the results cannot necessarily be generalized to other contexts. Patterns are likely to vary between different countries depending on how labour markets have evolved. In countries where low-paid jobs with low skill levels and low educational demands have grown more widespread, extrinsic work attitudes are likely to have become more prevalent. This might explain why the results in this study deviate from earlier case studies from the United States (e.g., Twenge et al., 2010). One question for future research is how different developments of the job structure are related to cross-country differences in work attitudes. Secondly, the included sub-periods do not cover every year within the study period. Thus, there is a risk that the results cannot be generalized to years or periods not included in this study. Indeed, the aim of the study was to cover a period that captured the important structural changes to the Swedish labour market, the most important being the changes in the job structure following the financial crisis of the early 1990s. The design of the study covers the period 1994-1996, which was a critical period with high unemployment resulting from layoffs in Swedish industry, but not the last years of the same decade. During the final years of the 1990s, patterns changed. The rates of employment among men increased while the effects of the financial crisis hit the public sector. Austerity programmes led to downsizing and layoffs in branches where most employees were women. Since we know that (i) during the early phase of the crisis it was predominately men who lost their jobs (and therefore were not included in the measurement of attitudes to work) and (ii) that men are more likely than women to express extrinsic attitudes, this might mean that results for the third sub-period, 1994-1996, cannot be generalizable to the years between the third and the fourth sub-period. However, this limit is not likely to affect the general conclusions of this study, that is, that extrinsic attitudes decreased across time, but that age-effects were stable and 
cohort-effects confirmed that the distribution of attitudes changes as working people grow older.

\section{Policy implications}

While the majority of Swedish workers hold attitudes that are less extrinsic, the youngest age-group do not follow this pattern. Around one-third of the 16-29 year-old Swedish workers identify with the description that '[t]his job is like any other job. You do what is expected of you, but the only thing that matters is the earnings'. This attitudinal lag is related to the generally weaker position of younger people on the labour market. Earlier research shows that, particularly since the Swedish financial crisis of the 1990s, it is the youngest workers who have the weakest employment security, the poorest working conditions, the lowest wages, and the highest prevalence of mental-health problems (Strandh et al., 2012). Furthermore, for these young workers, labour-market entry and establishment have been delayed owing to longer educational periods, protracted unemployment, and weaker employment security.

If policy-makers aim to change younger peoples' work attitudes, and thereby decrease age-differences regarding work attitudes, the results of this study imply that researchers and policy-makers should engage more thoroughly in demand-side factors, that is to say, how conditions on the labour market and in the workplace affect work attitudes. The significance of class and work environment - the psychosocial dimension in particular - suggests that such measures should include an examination of how increases in levels of skill and improvements in work environments directed to improve the balance between demand, control, and social support in work could increase workers' capability, interest, and willingness to participate on the labour market.

\section{References}

Alvesson, M., \& Willmott, H. (1992). Critical management studies. London: Sage.

Atkinson, R. L., Atkinson, R. C., Smith, E. E., Bem, D. J., \& Hilgard, E. R. (1990). Introduction to psychology. San Diego: Harcourt Brace Jovanovich. 
Benner, M. \& Bundgaard Vad, T. (2000). Sweden and Denmark: Defending the welfare state. In F. W. Scharpf \& V. A. Schmidt (eds.), Welfare and work in the open economy. Volume II: Diverse responses to common challenges (pp. 399-467). Oxford: Oxford University Press.

Berglund, T. (2001). Attityder till arbete $i$ Västeuropa och USA [Attitudes towards work in Western Europe and the United States]. Gothenburg: Gothenburg University.

Bihagen, E. (2000). The significance of class: studies of class inequalities, consumption and social circulation in contemporary Sweden. Umeå, Sweden: Umeå University.

Bolton, S. (Ed.) (2007). Dimensions of dignity at work. Amsterdam: Butterworth-Heinemann.

Braverman, H. (1974). Labor and monopoly capital. New York: Monthly Review Press.

Carstensen, L. L., Isaacowitz, D. M., \& Charles, S. T. (1999). Taking time seriously: A theory of socioemotional selectivity. American Psychologist, 54(3), 165-81.

Carstensen, L. L., \& Mikels, J. A. (2005). At the intersection of emotion and cognition aging and the positivity effect. Current Directions in Psychological Science, 14(3), 117-121.

Cennamo, L., \& Gardner, D. (2008). Generational differences in work values, outcomes and person-organisation values fit. Journal of Managerial Psychology, 23(8), pp. 891-906.

Daly, M. (2000). A fine balance: Women's labor market participation in international comparison. In F. W. Scharpf \& V. A. Schmidt (Eds.), Welfare and work in the open economy. Volume II: Diverse responses to common challenges (pp. 467-511). Oxford: Oxford University Press.

de Vroom, B., \& Guillemard, A-M. (2002). 'From externalisation to integration of older workers: Institutional changes at the end of the worklife'. In J. G. Andersen \& P. H. Jensen (Eds.) Changing labour markets, welfare policies and citizenship (pp. 183-208). Glasgow: The Policy Press.

Ebbinghaus, B. (2006). Reforming early retirement in Europe, Japan and the USA. Oxford: Oxford University Press.

Edlund, J., \& Hult, C. (2008). Age and labour market commitment in Germany, Denmark, Norway and Sweden. Work, Employment and Society, 22(1), pp. 109-28. 
Esser, I. (2005). Why work?: comparative studies on welfare regimes and individuals' work orientations (Doctoral dissertation, Stockholm).

Foucault, M. (2007). Security, territory, population: Lectures at the College De France 1977-78. London: Penguin.

Goldstein, E. B. (1994). Psychology. Pacific Grove, Belmont: BrooksCole.

Goldthorpe, J. H., Lockwood, D. Bechhofer, F. \&Platt, J. (1967). The affluent worker and the thesis of embourgeoisement: some preliminary research findings. Sociology, 1(1), pp. 11-31.

Gould, R., Ilmarinen, J., Järvisalo, J., \& Koskinen, S. (2008). Dimensions of work ability. Results of the Health 2000 Survey. Helsinki: Finnish Institute of Occupational Health.

le Grand, C., Szulkin, R., \& Tåhlin, M. (2002). Har jobben blivit mer kvalificerade? Kvalifikationskravens förändringar i Sverige under tre decennier (Have jobs become more qualified? Changes in qualification requirements during three decades in Sweden). In K. Abrahamsson, L. Abrahamsson, T. Björkman, P. E. Ellström, \& J. Johansson (Eds.), Utbildning, kompetens och arbete [Education, competence and work]. Lund: Studentlitteratur.

Guillemard, A-M,. \& Argoud, D. (2004). 'France: A country with a deep early exit culture'. In T. Maltby, B. De Vroom, M.-L. Mirabile, \& E. Øverbye (Eds.) Ageing and transition to retirement. A comparative analysis of European welfare states (pp. 165-185). Cornwall: Ashgate.

Hakanen, J. J., Bakker, A. B., \& Schaufeli, W. B. (2006). Burnout and work engagement among teachers. Journal of School Psychology, 43, pp. 495-513.

Herzberg, F., Mausner, B., \& Snyderman, B. B. (1993). The motivation to work. New Jersey: Transaction Publishers.

Hosmer, D. W., \& Lemeshow, S. (2000). Applied logistic regression. New York: Wiley.

Hult, C. (2004). The way we conform to paid labour: Commitment to employment and organization from a comparative perspective. Umeå, Sweden: Umeå University.

Hult, C., \& Svallfors, S. (2002). Production regimes and work orientations: a comparison of six western countries. European Sociological Review, 18(3), pp. 315-331.

Johansson, M. (1997). Inställning till arbetet [Attitudes towards work]'. In G. Cigéhn \& M. Johansson (Eds.) Klassidentitet i upplösning? Om 
betydelsen av klass, politik och arbete i 90-talets Sverige [Class identity in decline? On the significance of class, politics and work in Sweden in the 1990s] (pp. 125-150). Umeå Studies in Sociology No. 111. Umeå: Umeå University.

Kreuger, A. B., \& Meyer, B. D. (2002). Labor supply effects of social insurance. Amsterdam: National Bureau of Economic Research.

Laslett, P. (1989). A fresh map of life: the emergence of the third age. London: Widenfeld and Nicholson.

Lidwall, U. (2011). Hade vi en sjukskrivningsepidemi? Utveckling och orsaker [Did we experience an epidemic in sickness absence? Developments and causes]. In Mellan arbete och sjukdom [Between work and illness], Social Insurance Report 2011:3, 41-60.

Lindbeck, A. (1995). Welfare state disincentives with endogenous habits and norms. The Scandinavian Journal of Economics, 97(4), pp. 477-494.

Liu, Y., \& Lei, Y. (2011). The connotation of work values: A preliminary review. Asian Social Science, 8(1), pp. 47-68.

Lubinski, D., Schmidt, D. B., \& Benbow, C. P. (1996). A 20-year stability analysis of the study of values for intellectually gifted individuals from adolescence to adulthood. Journal of Applied Psychology, 81(4), 443451.

Mather, M., \& Carstensen, L. L. (2005). Aging and motivated cognition: The positivity effect in attention and memory. Trends in cognitive sciences, 9(10), pp. 496-502.

Mathieu, J. E., \& Zajac, D. M. (1990). A review and meta-analysis of the antecedents, correlates, and consequences of organizational commitment. Psychological Bulletin, 108, pp. 171-94.

Meglino, B. M., \& Ravlin, E. C. (1998). Individual values in organizations: Concepts, controversies, and research. Journal of Management, 24(3), 351-389.

Mulinari, D., \& Neergaard, A. (2004). Den nya svenska arbetarklassen: rasifierade arbetares kamp inom facket [The new Swedish working class: racialized workers' struggle in trade unions]. Umeå: Boréa.

Noon, M. \& Blyton, P. (2007). The realities of work: Experiencing work and employment in contemporary society. Bristol: Palgrave. 
Nordenmark, M. \& Stattin, M. (2009). Psychosocial wellbeing and reasons for retirement in Sweden. Ageing and Society, 29(3), 413.

OECD. (1988). The future of social protection. Paris: OECD Publishing.

OECD. (2006). Live longer, work longer. Paris: OECD Publishing.

OECD. (2010). Labour force statistics. Available at: http://stats.oecd.org/Index.aspx.

Sayers, S. (2005). Why work? Marx and human nature. Science and Society, 69(4), 606-616.

Schaie, K. W. (1965). A general model for the study of developmental problems. Psychological bulletin, 64(2), 92.

SOU (2004). Vem tjänar på att arbeta? [Who gains from working?]. Stockholm: Ministry of Finance, Offentliga förlaget.

SOU (2011). The long-term survey of the Swedish economy. Stockholm: Ministry of Finance, Offentliga förlaget.

Stamov-Roßnagel, C. \& Hertel, G. (2010). Older workers' motivation: against the myth of general decline. Management Decision, 48(6), 894-906.

Strandh, M., Nordlund, M. \& Hammarström, A. (2012). Youth unemployment, youth programs and mental health scarring in Sweden: long term mental health effects of two different forms of unemployment experiences. In E. Chiapero \& P. Martinetti (Eds.) A comparison of effects on capabilities in transitions to the labour market (page numbers). Bielefeld: Workable Research Consortium.

Svallfors, S., Goul Andersen, J., \& Halvorsen, K., (2001). Work orientations in Scandinavia: A comparison of Denmark, Norway and Sweden. Acta Sociologica, 44(2), 139-56.

Thompson, P. \& McHugh, D. (1990). Work organisations: A critical introduction. Wiltshire: Palgrave.

Twenge, J. M., Campbell, S. M., Hoffman, B. J., \& Lance C. E. (2010). Generational differences in work values: Leisure and extrinsic values increasing, social and intrinsic values decreasing. Journal of Management, 36(5), 1117-1142.

Vogel, J. \& Häll, L. (Eds.) (2006). Living conditions of the elderly: Work, economy and social networks 1980-2003. Stockholm: Statistics Sweden.

Vogel, J. \& Stattin, M. (2006). Äldres sysselsättning och arbetsmiljö [Older workers' employment and work environment]. In J. Vogel \& L. Häll 
(Eds.) Living conditions of the elderly: Work, economy and social networks 1980-2003, 49-72. Stockholm: Statistics Sweden.

Vogel, J. (2006). De äldres hälsoutveckling [Older people's health development]. In J. Vogel \& L. Häll (Eds.) Living conditions of the elderly: Work, economy and social networks 1980-2003, 273-328. Stockholm: Statistics Sweden.

Wikman, A. (2005). Om arbetsengagemang och andra motiv för arbetet än ekonomiska [On engagement in work and other extra-economical motives to work]. Stockholm: Arbetslivsinstitutet.

Åberg, R. (2004). Vilka jobb har skapats på den svenska arbetsmarknaden de senaste decennierna? [What kinds of jobs have been created in the Swedish labour market in recent decades?], Ekonomisk debatt 7/2004 (32), 37-46. 